\title{
Nicotine Nasal Spray
}

National Cancer Institute

\section{Source}

National Cancer Institute. Nicotine Nasal Spray. NCI Thesaurus. Code C16162.

A nasal spray composed of an aqueous solution containing the alkaloid nicotine with nicotine replacement activity. Upon administration of the spray into the nostrils, nicotine is taken up from the nasal mucosa into the bloodstream. Although nicotine binds to nicotinic cholinergic receptors at the autonomic gang lia, adrenal medulla and at neuromuscular junctions as well, the binding of nicotine to the receptors in the central nervous system (CNS) appears to be responsible for the addictive nature of nicotine. Binding to CNS nicotinic acetylcholine receptors causes the release of the neurotransmitter dopamine which appears to be responsible for the addiction of nicotine. Administration of nicotine may prevent nicotine craving and may help with the withdrawal symptoms associated with smoking cessation. 